\title{
Rethinking Plan A for Sustainable HCl
}

\author{
removed for submission
}

\begin{abstract}
This paper challenges the sustainable HCI community to move away from a focus on demand and instead address climate change as a supply problem. We identify a new route to impact, namely to focus on addressing the psychological barriers that prevent the political action needed to affect the supply of fossil fuels. Five barriers are explored as a means of revealing new research objectives for the community.
\end{abstract}

\section{Author Keywords}

Sustainability, climate change, supply, psychological barriers, activism.

\section{ACM Classification Keywords}

H.5.m. Information Interfaces and Presentation (e.g. HCI): Miscellaneous

\section{INTRODUCTION}

This paper is inspired by a concern that sustainable HCI seems to be focusing on a series of minimal-impact solutions for an increasingly serious and imminent problem, namely climate change. The stark truth is that despite a rapid growth in sustainability research in HCI and the more 'technical' fields within computing, global carbon emissions are continuing to increase year on year [19], at a time when these emissions must drastically decrease.

Influential past $\mathrm{CHI}$ publications $[3,10]$ have identified that $45 \%$ of our HCI research aims to reduce energy consumption or otherwise adopt pro-environmental behavior change. Hence the current 'Plan A' for sustainable HCI is exemplified by techniques that encourage incremental reductions in energy consumption. However, as Mankoff [22] notes, even if we pursue this strategy alongside efforts such as smart grid and other IT solutions, 'the maximum impact [computing] can have is .6 percent of global energy emissions, assuming that we had a systemic impact on all energy wasted post-grid (not just home heating and cooling in a few households in one or two developed countries).' Since the average annual growth in emissions for the past 160 years is approximately $1.8 \%$ [19], and from 2000 to 2010 appears to be closer to $2.3 \%$ growth [1], our maximum potential impact is not even enough to offset this rate of growth, let alone enable overall reductions.

For those who recognize the scale of this challenge and the limitations of the tools sustainable HCI has identified for

Paste the appropriate copyright statement here. ACM now supports three different copyright statements:

- ACM copyright: ACM holds the copyright on the work. This is the historical approach.

- License: The author(s) retain copyright, but ACM receives an exclusive publication license.

- Open Access: The author(s) wish to pay for the work to be open access. The additional fee must be paid to ACM.

This text field is large enough to hold the appropriate release statement assuming it is single spaced. addressing it, the natural question is 'What if sustainability doesn't work out?' [30]. Here we see the emergence of Collapse Informatics [31], which pragmatically proposes a Plan B: 'If, as increasingly seems likely, humanity is unable to prevent dramatic global change, then adaptation to these transformations will be of growing relevance' [30].

We agree that if Plan A (preventing climate change through incremental reductions in energy consumption) is unlikely to succeed, preparing for Plan B is necessary; but we argue that it is only sensible to explore Plan B if we simultaneously rethink our Plan A for sustainable HCI — i.e. re-evaluate and re-focus our current agenda. We therefore take up Mankoff's [22] challenge to envisage sustainable HCI contributions for targeting alternative indirect causes of climate change as a route to affecting more significant and impactful HCI research.

\section{CLIMATE CHANGE}

While there is some debate amongst climatologists about the amount of climate change that can be considered 'safe', 2 degrees Celcius is typically adopted as the limit [23]. Assuming this figure is roughly right, in practical terms this means that our proven fossil fuel reserves are approximately 4-5 times the amount we are able to safely burn before passing this 2 degree limit $[1,5,23]$.

This suggests that we cannot succeed by addressing climate change as a demand problem alone. Nevermind the fact that there appears to be a limit to the amount of energy savings people are capable of achieving before having to willingly sacrifice their standard of living [26, 29], an amount that appears to hover around 5-15\% reductions through persuasion and eco-feedback $[8,17]$. Even if by some means we help get the emissions of high-footprint nations down to their ambitious (though some still say inadequate [16]) $80 \%$ reduction targets $^{1}$, we are merely slowing our approach toward the 565 gigaton carbon dioxide limit our atmosphere can absorb before catalysing spiralling climate change $[15,23]$.

To the extent that the issue of supply is explored at all within $\mathrm{HCI}$, it is typically within the context of 'peak oil' as a potential catalyst for collapse [30]. Any serious commitment to climate change, however, must involve a strategy for getting fossil fuel companies to leave as much as $80 \%$ of their assets in the ground. By understanding the current barriers to doing so, we can begin to develop HCI solutions that affect these barriers. This is the subject of the remainder of the paper.

\section{ROUTES TO IMPACT FOR SUSTAINABLE HCI}

To begin, what would it take for fossil fuel companies to write off $80 \%$ of their assets? Clearly there needs to be an extremely compelling reason for them to write off \$20 trillion

\footnotetext{
1e.g. The UK's Climate Change Act commits Britain to reducing emissions $80 \%$ by 2050 as compared to 1990 s levels.
} 
(40\% of global GDP) $[1,13]$. This could include a combination of legislation of caps and taxes, and/or offering these companies (additional) subsidies to keep their assets in the ground. All of these take a significant amount of political will - enough, for example, to counteract the staggering $\$ 440,000$ spent daily by the top five oil companies in lobbying the US Congress [24]. It seems dangerous to assume this will is going to come directly from those in positions of power. But it seems possible that if the people of this planet demand it of their leaders, we could ultimately force a swift transition to renewable energies alongside significant investment in breakthrough carbon capture technologies, and succeed in averting the worst effects of climate change.

Many of the opportunities for re-visioning Plan A lie in the human race's ability to overcome the psychological barriers that are currently preventing us from taking action on climate change. Important work is being done to understand these barriers (e.g.[6, 7, 33]), and we propose below an initial fivepoint strategy for addressing the issues raised by this research.

\section{Addressing Values: Toward Caring}

Periods of prosperity, and the economic security this brings, tend to breed bigger-than-self concern for issues such as equality, civil rights, and protecting the environment [26]. In contrast, authoritarian and self-enhancement values - which have been shown to lead to reduced concern for issues such as climate change and sustainability [6] - tend to be strengthened by the feelings of economic insecurity currently being exacerbated by global recession.

Sustainable HCI often attempts to resolve this problem by leveraging concern about the economy into proenvironmental behavior, by designing feedback mechanisms that translate environmentally beneficial behavior change into cost savings (as discussed in [20]). Sustainable HCI could have a greater impact by specifically seeking to develop interactions and interventions that activate (self-transcendent) values that have been shown to increase concern about sustainability [6]. This has the potential to foster the emotional capacity to care about climate change, enabling people to overcome the self-interested tendencies that currently erode concern about this issue.

\section{Addressing Material Insecurity: Toward Caring Enough}

It is not uncommon to overhear pronouncements like, 'If we all lived like people in [insert developing nation here], we wouldn't have a sustainability problem.' We may, indeed, have much to learn from these nations about making do with less; and poverty does reliably correlate with relatively low emissions. But in the context of fostering lasting concern that can motivate political action (while also seeking a sustainability solution that advances social justice around the world), it is important to note that nations such as China, India and Brazil see the objective of raising standards of living as far more pressing and real than the projected problems of climate change. This is best expressed by the statement from a Chinese spokesman that, 'You cannot tell people who are struggling to earn enough to eat that they need to reduce their emissions' [26]. In other words, a perceived inability to meet basic needs (i.e. material insecurity) is a major impediment to taking action for climate change. Material insecurity is not just a problem for developing nations, however. It appears to be on the rise in recent years in wealthy nations, causing people to increasingly rate economic concerns as their top priority [26].

The strategy described previously to address values may go some way toward elevating climate change as a priority, but this would be further helped by developing interventions that are designed specifically to increase feelings of security. One new strategy for sustainable HCI, therefore, could be to enable and encourage local fiscalism [18]. The rationale for this angle is that material insecurity can lead to short-sighted decision making that feeds a disempowering cycle. For example, it makes people more likely to seek out the discounts (shortterm gain) that global mega-stores can offer, which removes wealth from local circulation and precipitates the decline of local businesses (long-term loss). By designing tools that reveal the long-term benefits of local spending and develop means of encouraging this spending - for example, through local currency initiatives [18] and/or gaming techniques that simultaneously reinforce the kinds of values suggested above - sustainable HCI could interrupt this cycle, and in doing so, help assuage the anxieties of material insecurity that currently displace concerns about climate change.

\section{Addressing Survival Anxiety: Toward Desire for Change}

By promoting consumer reductions as its primary avenue to impact, sustainable $\mathrm{HCI}$ has reinforced a framing of the climate change solution as 'sacrifice'. This 'sacrifice' frame collides with notions of 'progress' as a steady march of human improvement [14], and may threaten our identity as human beings. This triggers what psychoanalysts call 'survival anxiety' [33], i.e. not just anxiety about our physical survival, but also about the survival of our notion of ourselves as special and capable of remaking the world according to our wishes. When this human identity is threatened, we are more likely to think irrationally and engage in unhelpful behaviors.

Nordhaus \& Shellenberger [26] argue that this is the root cause of the failure of environmentalism to date, namely that environmentalism promotes a 'politics of limits, which seeks to constrain human ambition, aspiration, and power rather than unleash and direct them' [26, p. 17]. In order to overcome the disruptive influence of survival anxiety, sustainable HCI needs to replace rhetoric about sacrifice (and, indeed, 'collapse') with a vision of sustainability as the fulfilment of human potential. While partially a marketing challenge for sustainability generally, positive contributions in this area would include the design of aspirational futures, e.g. through exploration of design fictions [2, 32].

\section{Addressing Disavowal: Toward Empowerment}

An especially common form of denial of the reality of climate change is disavowal, which works to deflect anxiety by systematically distorting the truth. Disavowal tends to entrench thinking that climate change is 'none of my fault' while simultaneously increasing feeling that 'it is all my fault' [33], neither of which is helpful for promoting positive action. As 
noted by [11], sustainable HCI tends to locate the onus of responsibility for sustainability on the shoulders of individual consumers. We suggest this may feed this de-motivating spiral of disavowal.

Instead, sustainable HCI can work to disrupt this disavowal by providing greater clarity about the power relationships in play that contribute to the climate change problem. For example, visualizations or artistic or creative interventions may be utilized to powerfully showcase the data and facts that face us, illustrating complex inter-relationships between different agents, and capturing externalities presently hidden from public view. The ways in which the fossil fuel industry has systematically distorted the truth about climate change and influenced legislation (see [9] for examples) is one area where $\mathrm{HCI}$ and persuasive techniques may be employed to help people gain a sense of proportion about their own role in climate change as a necessary first step for identifying targets (e.g. the fossil fuel industry, politicians) for positive actions one can take, and spurring individuals and/or communities to take these actions. End User Development (EUD) is another important emerging field that aims to facilitate end-user empowerment [27] and could be utilized by citizens to further 'spread the word' of climate change realities. A further exciting opportunity is in more fully understanding the potential for the use of crowd-sourcing to better enable the sharing of 'problems and associated solutions, together with their underlying rationale' [27].

\section{Addressing Helplessness: Toward Activism}

The previous routes to impact focus on creating the conditions for people to be psychologically able to care about climate change and to want to do something about it. These are necessary but insufficient for generating the kind of political force needed for instigating meaningful policy change. Especially when people are fired up about the need to do something, struggling to identify steps that can be taken toward affecting change can provoke fatalism (e.g. 'We're all doomed, so what's the point?'). A similar exasperation can result from feelings that current methods of participation are insufficiently influential, e.g. being able to add one's name to an online petition.

A necessary contribution from sustainable HCI, therefore, would be to innovate technologically-mediated or technologically-enhanced forms of activism. As part of this effort, research that explores the history of successful political movements with a view toward revealing specific qualities that any design for activism should aim to support would help ensure that the resulting activism has a maximally positive impact for the cause.

\section{DISCUSSION}

Like everyone else, sustainable HCI researchers experience a psychological struggle with certain aspects of climate change. The initial years of sustainable HCI may be a manifestation of a particular kind of anxiety that is prone to 'omnipotent thinking' and employs a range of 'quick fixes' to the problem of climate change (and sustainability more broadly) (cf. [33, p. 33]). The inconvenient side effects of pursuing a route to sustainability based on these (consumption based) quick fixes is that 1) it 'deflect[s] pressure for government to adopt ambitious and potentially unpopular policies and regulations' [7], and 2) it reinforces the narrative that 'all will be well', a message that people are all too ready to believe.

In recent years, researchers (e.g. [3, 21, 22, 25, 28]) have begun to develop a new posture of 'active fatalism' [33] that acknowledges the insufficiency of these solutions to date but continues to seek opportunities for making a greater impact. In this mode, we have overcome disavowal and survival anxiety, and can tap into a renewed energy to fight for sustainability. The even more recent turn toward Collapse Informatics, however, seems to reflect the encroachment of helplessness, that there may be nothing sustainable HCI can do to help avert climate change. To the extent that this is grounded in the hope that the beginnings of collapse might serve as a psychological impetus for undertaking societal overhaul, Collapse Informatics may be seen as optimistic; but this hope does not align with the evidence that crisis tends to fuel the very emotional management strategies we have discussed which currently serve to prevent us from making headway on climate change.

Ultimately, we are offering the same suggestion for sustainable HCI researchers as we have for these researchers to offer the general pubic: to overcome helplessness, sustainable HCI researchers need new opportunities to engage in activism. Depending on the style of researcher, this may include confrontational forms such as 'adversarial design' [9] or 'quieter' forms of 'design activism' (cf. [12]). But assuming that sustainable HCI undertakes a strategy for affecting the supply side of climate change, the community cannot avoid being political. Becoming comfortable with being contentious is part of the work sustainable HCI researchers need to do to construct their identity as activists. Further discussions such the CHI'13 panel on activism [4] are needed to explore the implications of this changing job description.

\section{CONCLUSION}

The common wisdom is that talking about the reality of the crisis we face is too scary for people to handle. But avoiding discussing the seriousness of climate change only makes it that much more likely that our fears will become a reality. We have argued that any engineering solutions to climate change proposed by sustainable $\mathrm{HCI}$ can only succeed if they are coupled with political action, and that one route to promoting this political action is to address the barriers currently preventing this action. By presenting these hard truths, we hope that the challenge we have outlined is more inspiring than the current Plan A and Plan B.

\section{ACKNOWLEDGMENTS}

Removed for submission.

\section{REFERENCES}

1. Berners-Lee, M., and Clark, D. The Burning Question. Profile Books Ltd., 2013. 
2. Bleecker, J. Design fiction: A short essay on design, science, fact and fiction. Near Future Laboratory 29 (2009).

3. Brynjarsdóttir, H., Håkansson, M., Pierce, J., Baumer, E., DiSalvo, C., and Sengers, P. Sustainably unpersuaded: how persuasion narrows our vision of sustainability. In Proc. CHI'12, ACM (2012), 947-956.

4. Busse, D. K., Borning, A., Mann, S., Hirsch, T., Nathan, L. P., Grimes Parker, A., Shneiderman, B., and Nunez, B. Chi at the barricades: an activist agenda? In Proc. CHI EA '13, ACM (2013), 2407-2412.

5. Carbon Tracker Initiative. Unburnable carbon: Are the world's financial markets carrying a carbon bubble. Carbon Tracker Initiative (2011).

6. Crompton, T., and Kasser, T. Human identity: a missing link in environmental campaigning. Environment 52, 4 (2010), 23-33.

7. Crompton, T., and Thøgersen, J. Simple and Painless: The limitations of spillover in environmental campaigning. WWF-UK, February 2009.

8. Darby, S. The effectiveness of feedback on energy consumption. technical report, environmental change institute, university of oxford. A Review for DEFRA 486 (2006).

9. DiSalvo, C. Adversarial Design. The MIT Press, 2012.

10. DiSalvo, C., Sengers, P., and Brynjarsdóttir, H. Mapping the landscape of sustainable HCI. In Proc. CHI'10, ACM (2010), 1975-1984.

11. Dourish, P. HCI and environmental sustainability: the politics of design and the design of politics. In Proc. DIS '10, ACM (2010), 1-10.

12. Fuad-Luke, A. Design activism: beautiful strangeness for a sustainable world. Earthscan, 2009.

13. Fullerton, J. The big choice. Capital Institute [online] http://capitalinstitute.org/blog/big-choice-0\# .ujgMO7ye5q5, 2011.

14. Greer, J. M. The Long Descent. New Society Publishers, Gabriola Island, 2008.

15. Hansen, J., Sato, M., Kharecha, P., Beerling, D., Berner, R., Masson-Delmotte, V., Pagani, M., Raymo, M., Royer, D. L., and Zachos, J. C. Target atmospheric co2: Where should humanity aim? arXiv preprint arXiv:0804.1126 (2008).

16. Harrison, K. End of growth \& liberal democracy. Lecture, Australian Centre for Sustainable Catchments, University of Southern Queensland [online] http: //vimeo.com/41056934, April 2012.

17. Hazas, M., Brush, A. J. B., and Scott, J. Sustainability does not begin with the individual. interactions 19,5 (Sept. 2012), 14-17.
18. Helleiner, E. Think globally, transact locally: Green political economy and the local currency movement. Global society 14, 1 (2000), 35-51.

19. Jarvis, A., Leedal, D., and Hewitt, C. Climate-society feedbacks and the avoidance of dangerous climate change. Nature Climate Change 2, 9 (2012), 668-671.

20. Knowles, B. Re-imagining persuasion: designing for self-transcendence. In Proc. CHI EA '13, ACM (2013), 2713-2718.

21. Knowles, B., Blair, L., Hazas, M., and Walker, S. Exploring sustainability research in computing: Where we are and where we go next. In Proc. UbiComp '13, ACM (2013), 305-314.

22. Mankoff, J. HCI and sustainability: a tale of two motivations. interactions 19, 3 (May 2012), 16-19.

23. McKibben, B. Global warmings terrifying new math. three simple numbers that add up to global catastrophe-and that make clear who the real enemy is. Rolling Stone (2012).

24. McKibben, B. Do the math [video]. Available at http: //documentaryheaven.com/do-math-movie/, 2013.

25. Mollenbach, E., Hoff, J., and Hornbaek, K. HCI and sustainability: the role of macrostructures. In Proc. CHI EA'12, ACM (2012), 2159-2164.

26. Nordhaus, T., and Shellenberger, M. Break Through: Why We Can't Leave Saving the Planet to Environmentalists. Mariner Books, Boston, 2009.

27. Paternò, F. End user development: Survey of an emerging field for empowering people. ISRN Software Engineering (2013).

28. Pierce, J. Undesigning technology: considering the negation of design by design. In Proc. CHI '12, ACM (2012), 957-966.

29. Shove, E. Comfort, cleanliness and convenience. Berg Publishers, Oxford, 2003.

30. Tomlinson, B., Patterson, D. J., Pan, Y., Blevis, E., Nardi, B., Silberman, S., Norton, J., and LaViola, Jr., J. J. What if sustainability doesn't work out? interactions 19, 6 (Nov. 2012b), 50-55.

31. Tomlinson, B., Silberman, M. S., Patterson, D., Pan, Y., and Blevis, E. Collapse informatics: augmenting the sustainability \& ict4d discourse in hci. In Proc. CHI' 12, ACM (2012a), 655-664.

32. Wakkary, R., Desjardins, A., Hauser, S., and Maestri, L. A sustainable design fiction: Green practices. $A C M$ TOCHI (To appear) (2013).

33. Weintrobe, S. Engaging with climate change: Psychoanalytic and interdisciplinary perspectives. Routledge, 2013. 